\title{
Microbial contamination and disinfection methods of pacifiers
}

\author{
Paulo NELSON-FILHO', Márcia Costa LOUVAIN², Soraia MACARI ${ }^{3}$, Marília Pacífico LUCISANO', Raquel Assed \\ Bezerra da SILVA ${ }^{1}$, Alexandra Mussolino de QUEIROZ¹ ${ }^{1}$ Patrícia GATON-HERNÁNDEZ ${ }^{4}$, Léa Assed Bezerra da SILVA ${ }^{1}$
}

1- Universidade de São Paulo, Faculdade de Odontologia de Ribeirão Preto, Departamento de Odontopediatria, Ribeirão Preto, SP, Brazil.
2- Universidade de Iguaçu, Departamento de Odontologia, Itaperuna, RJ, Brazil.
3- Universidade Federal de Minas Gerais, Faculdade de Odontologia, Departamento de Clínica, Patologia e Cirurgia Odontológicas, Belo Horizonte, MG, Brazil.
4- Universitat de Barcelona, Facultat d'Odontologia, Departament d'Odontostomatologia, Barcelona, Spain.

Corresponding address: Marília Pacífico Lucisano - Departamento de Clínica Infantil, Universidade de São Paulo, Faculdade de Odontologia de Ribeirão Preto - Avenida do Café, s/n - Monte Alegre - 14040-904 - Ribeirão Preto - SP - Brazil - Phone: +55-16-3315-4143 - Fax: +55-16-3633-0999 - e-mail: marilia. lucisano@forp.usp.br

Submitted: June 11, 2015 - Modification: July 13, 2015 - Accepted: July 28, 2015

\section{ABSTRACT}

\begin{abstract}
bjectives: To evaluate the microbial contamination of pacifiers by Mutans Streptococci (MS) and the efficacy of different methods for their disinfection. Methods: Twenty-eight children were assigned to a 4-stage changeover system with a 1-week interval. In each stage, children received a new pacifier and the parents were instructed to maintain their normal habits for 1 week. After this time, the pacifiers were subjected to the following 4 disinfection methods: spraying with $0.12 \%$ chlorhexidine solution, Brushtox ${ }^{\circledR}$ or sterile tap water, and immersion in boiling tap water for 15 minutes. Microbiological culture for MS and Scanning Electron Microscopy (SEM) were performed. The results were analyzed statistically by Friedman's non-parametric test $(\alpha=0.05)$. Results: The $0.12 \%$ chlorhexidine spray was statistically similar to the boiling water $(p>0.05)$ and more effective than the Brushtox ${ }^{\circledR}$ spray and control $(p<0.05)$. The analysis of SEM showed the formation of a cariogenic biofilm in all groups with positive culture. Conclusions: Pacifiers become contaminated by MS after their use by children and should be disinfected routinely. Spraying with a $0.12 \%$ chlorhexidine solution and immersion in boiling water promoted better disinfection of the pacifiers compared with a commercial antiseptic toothbrush cleanser (Brushtox ${ }^{\circledR}$ ).
\end{abstract}

Keywords: Pacifiers. Chlorhexidine. Streptococcus mutans.

\section{NTRODUCTI ON}

The use of pacifiers is increasingly widespread in different modern cultures $^{30}$, being recommended 7 recently since pacifier sucking calms down children, reduces crying, improves sleep ${ }^{8}$, has analgesic effects, partially supplies the need for suction, and reduces the risk of sudden death in the first 6 months of life ${ }^{26}$. Furthermore, most pieces of evidence do not support any adverse relationship between pacifier use and breastfeeding duration or exclusivity ${ }^{11,18}$.

Pacifiers are in contact with saliva and oral microflora and can be a site for contamination, growth, and transmission of microorganisms in children $^{3}$. Their use has been associated with the occurrence of otitis media ${ }^{22}$, candidiasis $^{13}$, intestinal parasitic infections ${ }^{3}$, and dental caries $^{19,28}$. As
Mutans Streptococci (MS) are the main etiologic agents of dental caries in humans ${ }^{12}$, their adhesion to the pacifier's surface may increase the risk of caries in children.

In everyday life, pacifiers are not always subjected to disinfection after their use, only being washed in running water and dried. To the best of our knowledge, two in vitro studies ${ }^{2,16}$ have evaluated the contamination of pacifiers by cariogenic microorganisms and the use of disinfection methods so far, but no in vivo study has been conducted.

Considering chlorhexidine is seen as the gold standard antimicrobial agent ${ }^{14}$, a commercial antiseptic containing activated ethanol with biocides called Brushtox ${ }^{\circledR}$ has been recommended for cleaning toothbrushes ${ }^{15}$, and also that mothers usually boil their children's pacifiers before use, 
there is clinical applicability in evaluating the efficacy of these disinfection methods. Thus, the aim of this clinical study was to evaluate, in vivo, the microbial contamination of pacifiers by MS and the efficacy of these different methods for their disinfection.

\section{METHODS}

The present study was approved by the Ethics Committee (Process no. 2001.11.384.58.8) and written informed consents were obtained from all parents or guardians.

Twenty-eight children aged 2 to 4 years that did not receive previous dental treatment and did not make use of antibiotics or mouthwash solutions in the last 3 months participated in this study.

First, both parents/guardians and children received information on the importance of oral health. By using a table of random numbers, the children were assigned to a 4-stage changeover system with a 1-week interval between each stage. In each stage, the children used a new latex-based pacifier (Neopan ${ }^{\circledR}$ Artigos Infantis Ltda, Santo André, SP, Brazil) for 1 week. By the end of the 4 stages, each child had used 4 pacifiers subjected to the following 4 disinfection methods: spraying with $0.12 \%$ chlorhexidine solution (Periogard ${ }^{\circledR}$, Colgate Palmolive, Kolynos do Brazil Ltda, São Paulo, SP, Brazil) six times $(0.6 \mathrm{~mL})$, with Brushtox ${ }^{\circledR}$ Antiseptic Toothbrush Cleanser Spray (Dentox Limited, Warwickshire, England) or sterile tap water (control), and immersion in boiling tap water for 15 minutes. Periogard ${ }^{\circledR}$ and water were applied using a sterile plastic trigger spray bottle. One single professional performed all disinfection methods. Solutions were used in all stages, but each of them was used by a different group of children in each stage to minimize the occurrence of bias, which could interfere in the results.

After the use of disinfection methods, the pacifiers were individually stored in sterile closed containers for $1 \mathrm{~h}$ and subjected to microbiological processing. Three pacifiers (additional control) were removed from their original packages, not being used by children, and then subjected to the same microbiological procedures to verify if contamination could occur during manufacturing and/or packaging processes.

\section{Microbiologic analysis}

All pacifiers were placed in Borel's tubes containing $25 \mathrm{~mL}$ of bacitracin sucrose broth, which is a specific selective enrichment broth for MS prepared without trypan blue for $3-4$ days at $37^{\circ} \mathrm{C}^{16}$, 21,25 . Next, the pacifiers were gently withdrawn from their packages and were rinsed in the broth under gentle shakings to remove planktonic microbiota, leaving sessile bacteria adhered as "spike" or "mushroom-like" colonies/biofilms. All sides of the pacifiers were analyzed and the sessile colonies/biofilms of MS adhered to latex's surface (based on colony morphology) were counted by a blinded examiner under aseptic conditions, using a stereomicroscope (Nikon, Tokyo, Japan) with reflected light.

The number of colonies/biofilms of MS on the surface of latex after microbial culture was counted and expressed according to a 4-point scoring system: 0 for no MS colonies/biofilms or no bacterial growth; 1 for 1 -20 colonies/biofilms of MS; 2 for 21-50 colonies/biofilms of MS; 3 for $>50$ colonies/ biofilms of MS, which includes intense bacterial growth with confluent colonies, not allowing an accurate counting.

A sequence of steps was followed to confirm if microorganisms on the latex surface were MS: 4 to 5 colonies/biofilms representing bacterial growth were collected, transferred to tubes containing glass beads and $2 \mathrm{~mL}$ of phosphate buffer saline solution, and vortexed for $2 \mathrm{~min}$; the resulting suspension was seeded on modified SB-20 culture medium (Sucrose-Bacitracin Agar - SB-20M) ${ }^{23,24}$ and incubated in microaerophilia at $37^{\circ} \mathrm{C}$ for $72 \mathrm{~h}$. The colonies/biofilms were subjected to biochemical identification by tests using sugar fermentation, resistance to bacitracin and production of hydrogen peroxide ${ }^{24}$.

The microbiological results were analyzed statistically with Friedman's non-parametric test at a significance level of $5 \%$.

\section{Scanning electron microscopy (SEM) analysis \\ After microbiological processing, 4 representative} pacifiers of each group were fixed in $4 \%$ glutaraldehyde in cacodylate buffer, $\mathrm{pH} 7.4$, at $37^{\circ} \mathrm{C}$. After $48 \mathrm{~h}$, a sample of the latex surface of each pacifier was removed, post-fixed with $2 \%$ osmium tetroxide for $4 \mathrm{~h}$, dehydrated in ascending ethanol grades, and critical-point dried with liquid carbon dioxide. Samples were mounted on stubs, sputter-coated with gold, and examined on a scanning electron microscope (DSM 940A; Zeiss, Jena, Germany) operated at $15 \mathrm{kV}$ to evaluate the presence or the absence of contamination.

\section{RESULTS}

\section{Microbial culture}

The microbiologic results relative to the contamination of pacifiers by MS after $0.12 \%$ chlorhexidine, Brushtox ${ }^{\circledR}$ and tap water spraying, and immersion in boiling water are in Table 1.

Colonies/biofilms of MS were present in $5(17.86 \%)$ of the 28 pacifiers sprayed with 
chlorhexidine, whose score was of 2 (3.58\%), while the others scored 1 . The number of colonies/ biofilms ranged from 1 to 50 . When Brushtox ${ }^{\circledR}$ was used, colonies/biofilms of MS were present in 18
(64.29\%) of the 28 pacifiers, with scores from 1 to 3. The number of colonies/biofilms ranged from 1 to more than 50. After immersion in boiling water for 15 minutes, 6 (21.42\%) of the 28 pacifiers have

Table 1- Number of colonies/biofilms of mutans streptococci counted on the surface of pacifiers used for 7 days, according to the scores attributed for each disinfection: $0.12 \%$ chlorhexidine solution spray, Brushtox ${ }^{\circledR}$ Antiseptic Toothbrush Cleanser Spray, immersion in boiling tap water for 15 minutes or sterile tap water spray

\begin{tabular}{|c|c|c|c|c|}
\hline Case & $\begin{array}{l}0.12 \% \text { chlorhexidine } \\
\text { spray }\end{array}$ & Brushtox $^{\circledR}$ & Boiling water & Tap water spray \\
\hline 1 & 0 & 1 & 1 & 1 \\
\hline 2 & 0 & 1 & 1 & 3 \\
\hline 3 & 0 & 3 & 0 & 1 \\
\hline 4 & 1 & 1 & 1 & 1 \\
\hline 5 & 0 & 1 & 0 & 1 \\
\hline 6 & 0 & 1 & 0 & 2 \\
\hline 7 & 1 & 2 & 0 & 2 \\
\hline 8 & 0 & 0 & 1 & 1 \\
\hline 9 & 1 & 1 & 0 & 2 \\
\hline 10 & 0 & 1 & 1 & 1 \\
\hline 11 & 0 & 0 & 0 & 1 \\
\hline 12 & 0 & 1 & 0 & 1 \\
\hline 13 & 0 & 1 & 0 & 3 \\
\hline 14 & 1 & 1 & 0 & 2 \\
\hline 15 & 0 & 0 & 1 & 2 \\
\hline 16 & 0 & 0 & 0 & 3 \\
\hline 17 & 0 & 0 & 0 & 1 \\
\hline 18 & 0 & 0 & 0 & 1 \\
\hline 19 & 0 & 1 & 0 & 1 \\
\hline 20 & 0 & 0 & 0 & 3 \\
\hline 21 & 0 & 0 & 0 & 1 \\
\hline 22 & 0 & 2 & 0 & 1 \\
\hline 23 & 0 & 1 & 0 & 2 \\
\hline 24 & 0 & 1 & 0 & 1 \\
\hline 25 & 0 & 3 & 0 & 1 \\
\hline 26 & 0 & 1 & 0 & 2 \\
\hline 27 & 2 & 0 & 0 & 1 \\
\hline 28 & 0 & 0 & 0 & 1 \\
\hline Total & $5(17.85 \%)$ & 18 (64.28\%) & $6(21.42 \%)$ & $28(100 \%)$ \\
\hline
\end{tabular}

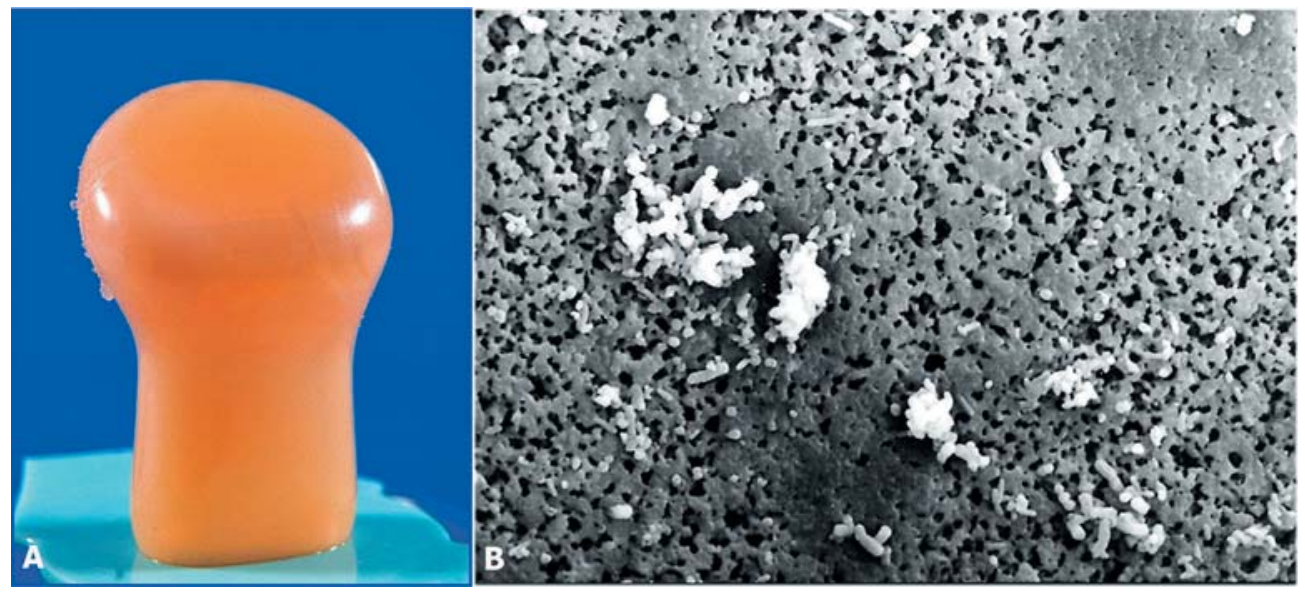

Figure 1- $0.12 \%$ chlorhexidine spray - Colonis/biofilms of Mutans streptococci after microbial culture (A) and scanning electron microscopy micrograph (B) 
showed MS colonization of score 1, with the number of colonies/biofilms ranging from 1 to 20 . The total of $28(100.0 \%)$ pacifiers sprayed with sterile tap water ended up being contaminated with MS, ranging from 1 to more than 50 colonies/biofilms, with scores from 1 to 3 . Seventeen (60.71\%) pacifiers scored $1,7(25 \%)$ scored 2, and $4(14.29 \%)$ scored 3. Figures $1 \mathrm{~A}-4 \mathrm{~A}$ show representative pacifiers of the 4 disinfection methods, respectively. There was no bacterial contamination in the 3 non-used pacifiers

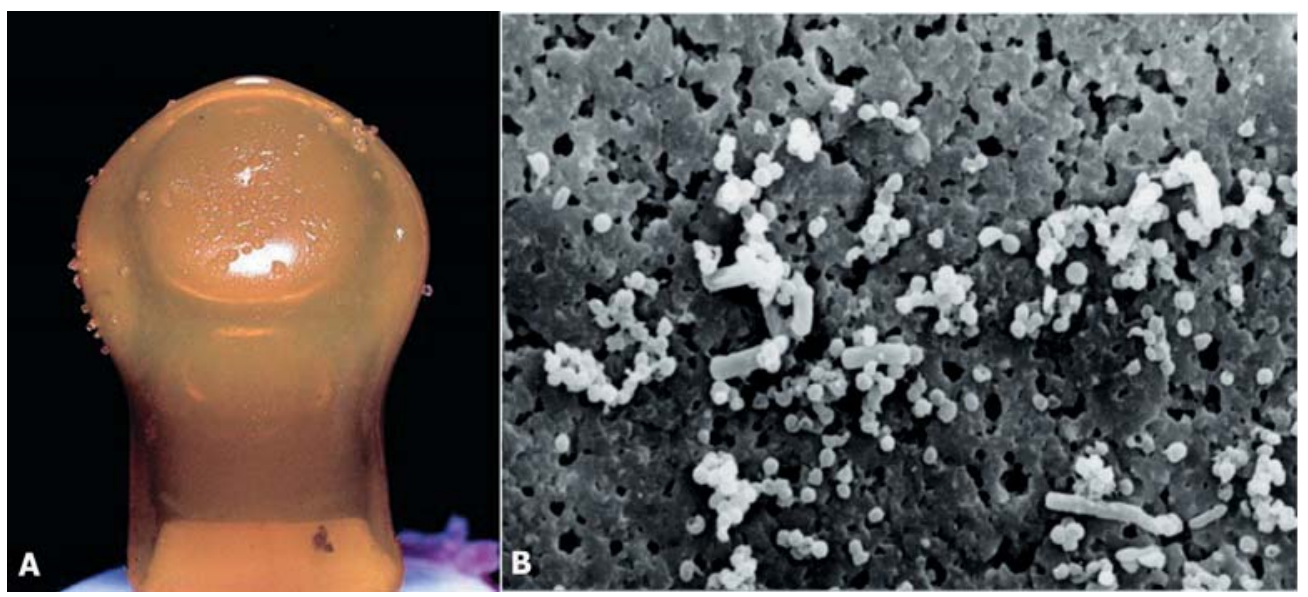

Figure 2- Brushto ${ }^{\circledR}$ - Colonies/biofilms of Mutans streptococci after microbial culture (A) and scanning electron microscopy micrograph (B)
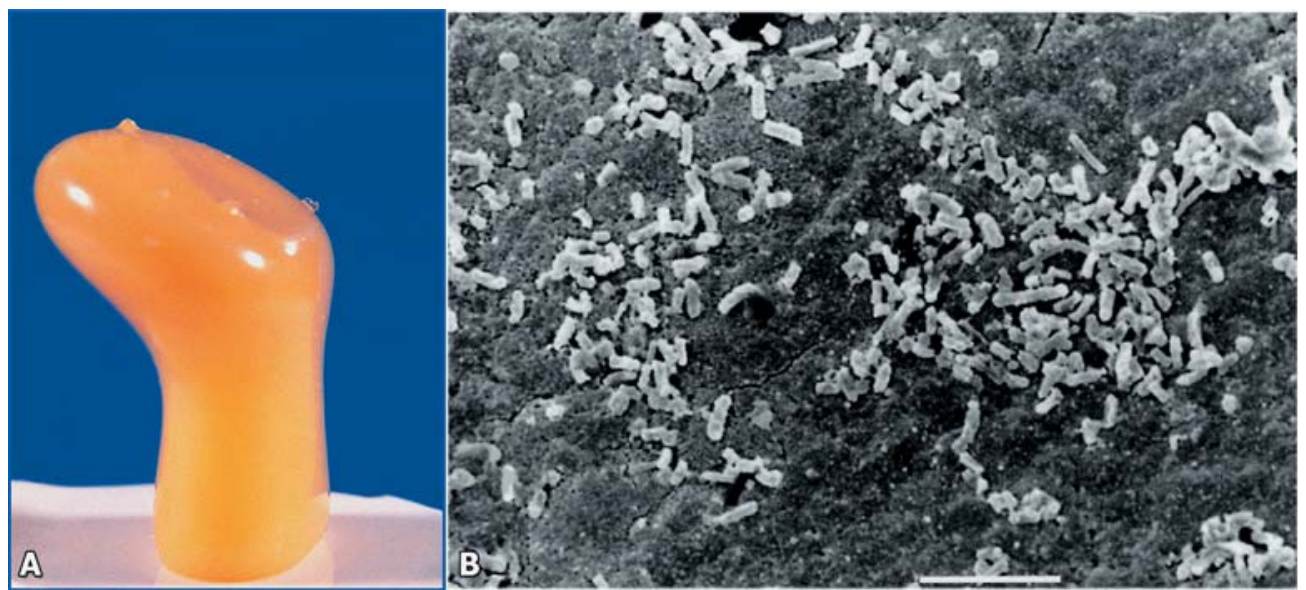

Figure 3- 15-minute immersion in boiling water - Colonies/biofilms of Mutans streptococci after microbial culture (A) and scanning electron microscopy micrograph (B)
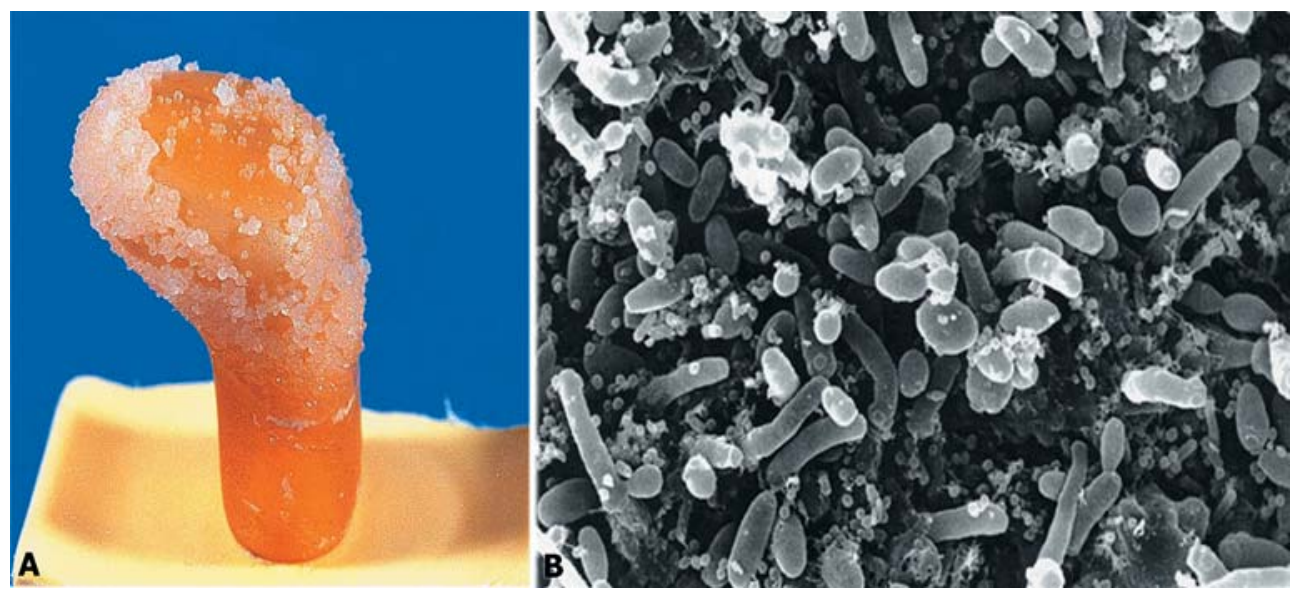

Figure 4- Sterile tap water spray - Colonies/biofilms of Mutans streptococci after microbial culture (A) and scanning electron microscopy micrograph (B) 
after incubation.

Regarding microbial contamination of the pacifiers' surfaces, there were significant differences between the $0.12 \%$ chlorhexidine solution, Brushtox ${ }^{\circledR}$, and immersion in boiling water in comparison with the sterile tap water (control) $(p<0.05)$. The $0.12 \%$ chlorhexidine spraying had similar efficacy when compared with the 15 -minute immersion in boiling water $(p>0.05)$; both methods had better efficacy $(p<0.05)$ than Brushtox ${ }^{\circledR}$ spraying. Sterile tap water spray, by its turn, presented the worst results $(p<0.05)$.

\section{SEM analysis}

When microbiological culture was positive under stereomicroscopy, colonies/biofilms of MS were also observed in the surface of pacifiers by SEM. Figures 1B-4B show representative pacifiers of the 4 disinfection methods.

\section{DISCUSSION}

Pacifiers are in contact with saliva and, therefore, with the oral microflora, being a potential site for biofilm growth ${ }^{1,13}$. As the microorganisms forming the dental plaque are components of the oral microflora, it may be hypothesized that they also adhere to the material of the pacifier's nipples ${ }^{3}$. In the present study, intense MS colonization was observed in the surface of pacifiers by both microbial culture and SEM analysis.

The enrichment medium for MS used in the present study was the SB-20M, with and without agar, which has been widely used in previous studies ${ }^{16,21,23-25}$. Bacitracin and high concentrations of sucrose are the main ingredients, allowing the growth and the identification of MS. The growth of oral streptococci, except for MS is inhibited by the bacitracin that is an antibiotic. The SB-20M medium is easy and inexpensive to prepare when compared with other selective media, also being reliable for the direct identification of $\mathrm{MS}^{23,24}$.

The importance of assessing the presence of microbial biofilms, specifically from the health standpoint, is that caries are still present in a large number of children. Despite being related to multifactorial conditions, such disease does not occur without the presence of microorganisms. In addition, studies ${ }^{9,29}$ have demonstrated that the earlier the colonization of children's oral cavity by MS (and the bigger its intensity), the higher the risk of developing dental caries.

In the present study, it was demonstrated that all pacifiers sprayed with tap water after their use were contaminated with MS. According to Ollila, et al. ${ }^{19,20}(1997,1998)$, extended pacifier sucking is a potential risk factor for dental caries in children, as this habit may modify the environmental conditions of the mouth because of the increase of available locations for microbial retention. This situation could be compared with a partial removable orthodontic appliance, which also contributes to microorganism's retention, creating low $\mathrm{pH}$ conditions in the mouth for extended time ${ }^{21}$. For this reason, Comina, et al. ${ }^{3}$ (2006) stated that an accurate disinfection of pacifiers is mandatory to limit contamination.

Brushtox ${ }^{\circledR}$ Antiseptic Toothbrush Cleanser is a product based on ethanol $(40 \% \mathrm{v} / \mathrm{v})$ and a biocide (paraben) with antimicrobial activity against bacteria and fungi on toothbrushes in vitro ${ }^{15}$. However, in the present study, $64.3 \%$ of in vivo pacifiers were contaminated after the application of this product and, despite being was superior to the control (tap water), the use of Brushtox ${ }^{\circledR}$ was less effective for the disinfection of pacifiers than $0.12 \%$ chlorhexidine spraying and boiling water. These results are in accordance with those of a previous clinical study on toothbrushes in which $0.12 \%$ chlorhexidine showed better results than Brushtox $^{\circledR} \quad(p<0.01)$ regarding the formation of colonies/biofilms of MS in the toothbrush bristles ${ }^{16}$.

Considering that the most indicated product for disinfection of toothbrushes is chlorhexidine ${ }^{16}$, this substance was also successfully tested in vitro for disinfection of pacifiers contaminated by Streptococus mutans in two previous studies ${ }^{2,17}$. Chlorhexidine is an antimicrobial agent with action against Gram-positive and Gram-negative microorganisms, facultative and strict anaerobes and aerobes. The S. mutans is highly sensitive to this agent ${ }^{5,6}$. According to the results of the present study, $0.12 \%$ chlorhexidine spraying had an $82.14 \%$ efficacy in eliminating MS from pacifier's surfaces. There was no significant difference between spraying $0.12 \%$ chlorhexidine and boiling water for 15 minutes, both procedures being equally effective in disinfecting pacifiers. According to the authors, however, the use of the $0.12 \%$ chlorhexidine spray seems to be more advantageous because it can be performed very quickly, optimizing the time spent with baby care; it is also safer, as the use of boiling water involves the risk of burns and reduces the expenses on gas and water, two exhaustible natural resources.

The question about selection for microbial resistance to chlorhexidine is controversial in dependence on frequency of use. Although some studies demonstrated no emergence of resistant microflora ${ }^{27}$, other studies reported that exposure to sublethal doses of chlorhexidine with high frequency can lead to the development of resistant strains ${ }^{4}$ and that some strains could have the potential to develop tolerance after prolonged exposure ${ }^{10}$. However, it is highlighted that, for the disinfection of pacifiers, the adverse effects of chlorhexidine are reduced because the application is performed 
outside the mouth (not by mouthwash), with no direct exposure of the mucosa, followed by thorough washing. It is recommended that, before use, the pacifier should be scrupulously washed with running tap water to remove dead microorganisms and residues of the antimicrobial agent.

In the present study, only one application of chlorhexidine was performed, justifying the need for additional studies to establish the ideal frequency of use (if one, two or three times per week or even daily, for example). As demonstrated by Peixoto, et al. ${ }^{21}$ (2011), the $0.12 \%$ chlorhexidine spray once or twice a week was equally effective on reducing the contamination by MS of removable orthodontic appliances.

Hospital and nurseries give strict instructions for the disinfection and sterilization of feeding bottles, but they do not provide similar instructions for pacifiers. Strict rules of hygiene and an efficient antibiofilm cleaning protocol should be established to address parents' concerns on the safety of pacifiers.

\section{CONCLUSION}

According to the results obtained, it was observed that cariogenic microorganisms colonize pacifiers and, therefore, it is strongly recommended to perform disinfection by boiling water for 15 minutes or, preferably, spraying an antimicrobial agent such as the $0.12 \%$ chlorhexidine, which is a safe, of low-cost, and practical method of disinfecting pacifiers.

\section{REFERENCES}

1- Brook I, Gober AE. Bacterial colonization of pacifiers of infants with acute otitis media. J Laryngol Otol. 1997;111:614-5.

2- Chamele J, Bhat C, Saraf T, Jadhav A, Beg A, Jagtap C, et al. Efficacy of microwaves and chlorhexidine for disinfection of pacifiers and toothbrushes: an in vitro study. J Contemp Dent Pract. 2012;13:690-4.

3- Comina E, Marion K, Renaud FN, Dore J, Bergeron E, Freney J. Pacifiers: a microbial reservoir. Nurs Health Sci. 2006;8:216-23.

4- Condell O, Iversen C, Cooney S, Power KA, Walsh C, Burgess $C$, et al. Efficacy of biocides used in the modern food industry to control Salmonella enterica, and links between biocide tolerance and resistance to clinically relevant antimicrobial compounds. Appl Environ Microbiol 2012;78:3087-97.

5- Emilson CG. Susceptibility of various microorganisms to chlorhexidine. Scand J Dent Res. 1977;85:255-65.

6- Emilson CG. Potential efficacy of chlorhexidine against mutans streptococci and human dental caries. J Dent Res. 1994;73:68291.

7- Gederi A, Coomaraswamy K, Turner PJ. Pacifiers: a review of risks vs benefits. Dent Update. 2013;40:92-4.

8- Goldman RD. Pacifier use in the first month of life. Can Fam Physician. 2013;59:499-500.

9- Köhler B, Andréen I. Mutans streptococci and caries prevalence in children after early maternal caries prevention: a follow-up at 19 years of age. Caries Res. 2012;46:474-80.
10- Kulik EM, Waltimo T, Weiger R, Schweizer I, Lenkeit K, FilipuzziJenny $E$, et al. Development of resistance of mutans streptococci and Porphyromonas gingivalis to chlorhexidine digluconate and amine fluoride/stannous fluoride-containing mouthrinses, in vitro. Clin Oral Investig. 2015;19:1547-53.

11- Lindau JF, Mastroeni S, Gaddini A, Di Lallo D, Fiori Nastro P, Patanè $M$, et al. Determinants of exclusive breastfeeding cessation: identifying an "at risk population" for special support. Eur J Pediatr. 2015;174:533-40.

12- Loesche WJ. Role of Streptococcus mutans in human dental decay. Microbiol Rev. 1986;50:353-80.

13- Mattos-Graner RO, Moraes AB, Rontani RM, Birman EG. Relation of oral yeast infection in Brazilian infants and use of a pacifier. ASDC J Dent Child. 2001;68:33-6.

14- Moshrefi A. Chlorhexidine. J West Soc Periodontol Periodontal Abstr. 2002;50:5-9.

15- Neal PR, Rippin JW. The efficacy of a toothbrush disinfectant spray - an in vitro study. J Dent. 2003;31:153-7.

16- Nelson-Filho P, Faria G, Silva RAB, Rossi MA, Ito IY. Evaluation of the contamination and disinfection methods of toothbrushes used by 24-to-48-month-old children. J Dent Child. 2006;73:1528.

17- Nelson-Filho P, Silva LA, Silva RA, Silva LL, Ferreira PD, Ito IY. Efficacy of microwaves and chlorhexidine on the disinfection of pacifiers and toothbrushes: an in vitro study. Pediatr Dent. 2011;33:10-3.

18- O'Connor NR, Tanabe KO, Siadaty MS, Hauck FR. Pacifiers and breastfeeding: a systematic review. Arch Pediatr Adolesc Med. 2009; 163:378-82.

19- Ollila $P$, Niemelä M, Matti U, Larmas M. Prolonged pacifiersucking and use of a nursing bottle at night: possible risk factors for dental caries in children. Acta Odontol Scand. 1998;56:233-7. 20- Ollila P, Niemelä M, Uhari M, Larmas M. Risk factors for colonization of salivary lactobacilli and Candida in children. Acta Odontol Scand. 1997;55:9-13.

21- Peixoto IT, Enoki C, Ito IY, Matsumoto MA, Nelson-Filho P. Evaluation of home disinfection protocols for acrylic baseplates of removable orthodontic appliances: a randomized clinical investigation. Am J Orthod Dentofacial Orthop. 2011;140:51-7. 22- Salah M, Abdel-Aziz M, Al-Farok A, Jebrini A. Recurrent acute otitis media in infants: analysis of risk factors. Int J Pediatr Otorhinolaryngol. 2013;77:1665-9.

23- Saravia ME, Nelson-Filho P, Ito IY, Silva LA, Silva RA, Emilson CG. Morphological differentiation between $S$. mutans and $S$. sobrinus on modified SB-20 culture medium. Microbiol Res. 2011;166:63-7.

24- Saravia ME, Nelson-Filho P, Silva RA, De Rossi A, Faria G, Silva LA, et al. Recovery of mutans streptococci on MSB, SB-20 and SB-20M agar media. Arch Oral Biol. 2013;58:311-6.

25- Saravia ME, Nelson-Filho P, Silva RA, Faria G, Rossi MA, Ito IY. Viability of Streptococcus mutans toothbrush bristles. J Dent Child (Chic). 2008;75:29-32.

26- Sexton S, Natale R. Risks and benefits of pacifiers. Am Fam Physician. 2009;79:681-5.

27- Sreenivasan P, Gaffar A. Antiplaque biocides and bacterial resistance: a review. J Clin Periodontol. 2002;29:965-74.

28- Vázquez-Nava F, Vázquez RE, Saldivar GA, Beltrán GF, Almeida AV, Vázquez RC. Allergic rhinitis, feeding and oral habits, toothbrushing and socioeconomic status. Effects on development of dental caries in primary dentition. Caries Res. 2008;42:141-7. 29- Wan AK, Seow WK, Purdie DM, Bird PS, Walsh LJ, Tudehope DI. A longitudinal study of Streptococcus mutans colonization in infants after tooth eruption. J Dent Res. 2003;82:504-8.

30- Wennergren G, Nordstrand K, Alm B, Möllborg P, Öhman A, Berlin $A$, et al. Updated Swedish advice on reducing the risk of sudden infant death syndrome. Acta Paediatr. 2015;104:444-8. 